\title{
Development of the Method for Forecasting and Calculating the Operation of Sorption Systems for Purifying the Generator Gas Based on Dolomite Use. Part I
}

\author{
Malko M.V. ${ }^{1}$, Vasilevich S.V. ${ }^{2}$, Mitrofanov A.V. ${ }^{3}$, Mizonov V.E. ${ }^{3}$ \\ ${ }^{1}$ Institute of Power Engineering of the National Academy of Sciences of Belarus, Minsk, \\ Republic of Belarus, \\ ${ }^{2}$ Belarusian State Academy of Aviation, Minsk, Republic of Belarus, \\ ${ }^{3}$ Ivanovo State Power Engineering University, \\ Ivanovo, Russian Federation
}

\begin{abstract}
A trend towards energy diversification creates the expansion of small energy facilities that involve the production of solid fuel generator gas, rather than its direct combustion. The economic indicators of such facilities significantly depend on the efficiency of the generator gas purification. A promising sorbent for the purification of the generator gas is dolomite. When working as a sorbent, dolomite particles usually form a layer, through which the generator gas that is heating them is filtered. The objective of the study is to determine kinetic parameters of the thermal decomposition of dolomite, depending on the size of the sample. It was achieved using the thermogravimetric study of the thermal decomposition of single dolomite particles under static conditions at various temperatures. The most significant scientific result was that a dependence of the kinetic parameters of the gross reaction on the size of the initial particle is revealed, and a regression equation was proposed for its quantitative assessment. In addition, since the heat treatment process of the material was fairly long lasting, and the sizes of the particles allowed them to be referred to thermally thin bodies, it was inferred that the effect of a grain size on the reaction kinetics should be explained through the description of the evacuation process of gaseous reaction products from the material. The significance of the results of the study lies in the fact that a particle size must be considered as a factor that affects the progress of the technological process, which increases the reliability of the calculation of sorption-catalytic systems based on the use of dolomite.
\end{abstract}

Keywords: generator gas, dolomite, thermal decomposition, sorbent, thermogravimetric analysis, kinetics of decomposition, generator gas purification system.

DOI: https://doi.org/10.52254/1857-0070.2021.3-51.07

UDC: $\mathbf{5 4 3 . 5 7 3}$

Perfectarea metodei pentru pronoză și calculul de funcționare a sistemelor de sorbție pentru curățarea gazului generator cu utilizarea de dolomită. Partea I

${ }^{1}$ Malko M.V., ${ }^{2}$ Vasilevici S.V., ${ }^{3}$ Mitrofanov A.V., ${ }^{3}$ Mizonov V.E.

${ }^{1}$ Institutul de Energetică al Academiei de Științe Naționale din Belarus, Minsk, Republica Belarus,

${ }^{2}$ Academia de Stat de Aviație din Belarus, Minsk, Republica Belarus,

${ }^{3}$ Universitatea de Stat de energetică din Ivanovo,

Ivanovo, Federația Rusă

Rezumat. În prezent există tendința de a diversifica sectorul energetic și de a-și extinde nişa de combustibil solid. Indicatorii economici ai unor astfel de instalații electrice la scară mică depind în mod substanțial de eficiența tehnologiei de purificare a gazelor generatoare. Dolomitul este un catalizator sorbent promițător pentru purificarea gazului generator, a cărui utilizare în aceste scopuri este justificată la nivel calitativ de o soluție tehnologică. Predicția cantitativă a performanței sistemelor de curățare a gazelor generatoare este o sarcină destul de dificilă, iar îmbunătățirea instrumentelor pentru proiectarea, operaționalul și calculele de optimizare a acestor sisteme este extrem de urgentă. Când lucrează ca catalizatori și absorbanți, particulele de dolomită sunt de obicei organizate într-un strat prin care este filtrat gazul generator care le încălzește. Scopul acestei lucrări este îmbunătățirea metodei de predicție și calcul a funcționării sistemelor de sorbție pentru curățarea gazului generator pe bază de dolomită. Acest obiectiv este atins prin studii termogravimetrice ale descompunerii termice a particulelor de dolomit unic în condiții statice la diferite temperaturi și determinarea valorilor parametrilor cinetici ai procesului în funcție de mărimea (masa) eșantionului studiat. Cel mai important rezultat al studiului

(C) Малько М.В., Василевич С.В.,

Митрофанов А.В., Мизонов В.Е., 2021 
este că a fost dezvăluită dependența parametrilor cinetici ai reacției brute de dimensiunea particulei iniţiale (masa probei) şi a fost propusă o ecuație empirică pentru evaluarea sa cantitativă. Semnificaţia rezultatelor cercetării constă în includerea în luarea în considerare a dimensiunii particulelor ca factor care influențează cursul procesului tehnologic, ceea ce crește fiabilitatea calculului sistemelor catalitice de sorbție bazate pe utilizarea dolomitei.

Cuvinte-cheie: generator gas, dolomite, thermal decomposition, sorbent, thermogravimetric analysis, kinetics of decomposition, generator gas purification system.

\section{Совершенствование метода прогнозирования и расчета работы сорбционных систем очистки генераторного газа на основе доломита. Часть I \\ ${ }^{1}$ Малько М.В., ${ }^{2}$ Василевич С.В., ${ }^{3}$ Митрофанов А.В., ${ }^{3}$ Мизонов В.Е. \\ ${ }^{1}$ Институт энергетики НАН Беларуси, Минск, Республика Беларусь, ${ }^{2}$ Белорусская государственная академия авиации, Минск, Республика Беларусь, ${ }^{3}$ Ивановский государственный энергетический университет, \\ Иваново, Российская Федерация}

Аннотация. В настоящее время наблюдается тенденция к диверсификации энергетики и расширению ее твердотопливной ниши. Следствием этой тенденции является расширение использования малых энергетических объектов (когенерационных электростанций), предполагающих получение генераторного газа из местного твердого топлива, а не прямое его сжигание. Экономические показатели подобных объектов малой энергетики существенным образом зависят от эффективности технологии очистки генераторного газа. Перспективным катализатором-сорбентом для очистки генераторного газа является доломит, использование которого для этих целей обосновано на качественном уровне технологическим решением. Количественное прогнозирование показателей систем очистки генераторного газа достаточно сложная задача, а совершенствование инструментов для проектирования, эксплуатационных и оптимизационных расчетов этих систем является крайне актуальным. При работе в качестве катализатора и сорбента частицы доломита обычно организуются в слой, через который фильтруется нагревающий их генераторный газ. Цель данной работы состоит в совершенствовании метода прогнозирования и расчета работы сорбционных систем очистки генераторного газа на основе доломита. Поставленная цель достигается за счет термогравиметрического исследования термического разложения одиночных частиц доломита в статических условиях при различных температурах и определении значений кинетических параметров процесса в зависимости от размера (массы) исследуемого образца. Наиболее существенным результатом исследования является то, что выявлена зависимость кинетических параметров брутто-реакции от размера исходной частицы (массы навески) и предложено эмпирическое уравнение для ее количественной оценки. Кроме того, поскольку время тепловой обработки материала было достаточно велико, а размер частиц позволяет отнести их к термически тонким телам, то было сделано заключение, что влияние размера зерен на кинетику реакции следует объяснять через описание процесса эвакуации газообразных продуктов реакции из материала. Значимость результатов исследования состоит во включении в рассмотрение размера частицы в качестве фактора, влияющего на ход технологического процесса, что повышает достоверность расчета сорбционно-каталитических систем, основанных на применении доломита.

Ключевые слова: генераторный газ, доломит, термическое разложение, сорбент, термогравиметрический анализ, кинетика разложения, система очистки генераторного газа.

\section{ВВЕДЕНИЕ}

В настоящее время наблюдается тенденция к поиску решения проблем энергетической эффективности производств, диверсификации энергетики, в том числе за счет вовлечения неиспользуемых ранее видов топлива и/или расширения диапазона исходных характеристик используемых топлив. При этом интенсивно развивается системы тепловых электрических станций (ТЭС), обладающих сравнительно малой мощностью, использующих различные виды местного топлива [1-4].
Подобные малые энергетические объекты, как правило, предполагают получение генераторного газа, а не прямое сжигание топлива [3-5].

Их эффективность в настоящее время существенно лимитируется несовершенством процесса очистки и охлаждения генераторного газа при высокой стоимости (до 15-20\% от общей цены строительства ТЭС с парогазовой установкой [3]) аппаратурного оформления необходимых для этого систем [3-5].

Перспективным катализатором-сорбентом для очистки генераторного газа является доломит. Использование доломита для этих 
целей обосновано на качественном уровне технологическим решением [4-5]. Продукты разложения доломита ( $\mathrm{CaO}$ и $\mathrm{MgO})$, связывают диоксид углерода $\left(\mathrm{CO}_{2}\right)$, содержащиеся в газогенераторном газе, образуя карбонаты кальция и магния соответственно $\left(\mathrm{CaCO}_{3}\right.$ и $\left.\mathrm{MgCO}_{3}\right)$.

При работе в качестве сорбента и катализатора частицы доломита обычно организуются в неподвижный слой, через который фильтруется генераторный газ. Подобный слой является объектом с распределенными параметрами и технологическая задача состоит в том, чтобы в аппарате были сформированы условия, обеспечивающие разложение доломита с необходимой скоростью. Продуктивное решение указанной задачи маловероятно, если нет достаточно простых, но физически адекватных макрокинетических моделей термического разложения доломита.

Таким образом, первоосновой для расчета аппаратуры для очистки генераторных газов является достаточный уровень знания о реализации процесса в одиночной частице и ключевых факторах, влияющих на этот процесс.

Ситуативный научный контекст формирования этих знаний, на наш взгляд, достаточно противоречив. С одной стороны, в настоящее время достаточно широк фронт исследовательских работ, посвященных этой проблеме [5-17]. С другой стороны, научный поиск осуществляется в парадигме теоретического материаловедения: авторы, излишне детализируя микро- и наноструктурные преобразования материала и эффекты, оставляют вне зоны своего внимания технологические аспекты процесса.

Так в работах [6-8] затронуты вопросы относительно действительного механизма термопреобразования доломита. В работе [7] приведены результаты, свидетельствующие о топотактическом механизме реализации первичных структурных преобразований при термическом разложении кальцита, и показано, что сам процесс разложения может быть описан как реакция первого порядка.

Топотактический механизм реакции термического разложения доломита подтверждается и результатами исследования [8], при этом отмечается, что на начальной стадии процесса происходит формирование гранецентрированного кубического смешанного оксида $\mathrm{Ca}_{0.5} \mathrm{Mg}_{0.5} \mathrm{O}$, который затем служит источником ориентированных кристаллов $\mathrm{CaO}$ и $\mathrm{MgO}$ [8]. Оба исследования выполнены с привлечением схожего инструментария: для определения параметров общей (брутто) кинетики используется термогравиметрический анализ, методы электронной микроскопии и рентгеновской дифрактометрии применены для микротекстурного анализа материала.

Однако, несмотря на общие цели и схожий инструментарий, авторы исследований [7-8] делают не вполне одинаковые выводы.

Так, не до конца определенным остается вопрос о влиянии накопления продуктов реакции $\left(\mathrm{CO}_{2}\right)$ в исследуемых образцах при их тепловой обработке на кинетику процесса.

Авторы [8] делают вывод, что давление $\mathrm{CO}_{2}$ не оказывает значимого влияния на скорость завершения реакций, в то же время в работе [7] указывается на критическую значимость указанного эффекта и на результаты термогравиметрического анализа (массу образца).

Другим вопросом, который также остается дискуссионным, является оценка кинетических параметров брутто-реакции. В исследованиях [5-18] можно встретить весьма существенно отличающиеся оценки ключевых кинетических параметров: эффективной энергии активации (от 97 кДж/моль [10] до 234 кДж/моль [18]), предэкспоненциальных множителей кинетического уравнения (от $0.1762 \cdot 10^{4} \mathrm{c}^{-1}$ [10] до $\left.0.2483 \cdot 10^{8} \mathrm{c}^{-1}[15]\right)$. Естественно, что подобные значительные расхождения указанных кинетических параметров связаны выбором эмпирического уравнения реакции термического разложения доломита.

Необходимо отметить, что число методов кинетической обработки достаточно велико (подробный анализ методов можно найти в работе [19]), и их использование ожидаемо приводит к получению несовпадающих оценок кинетических коэффициентов $[10,19]$.

В частности, в работе [10] выполнена идентификация кинетических параметров реакции термического разложения доломита тремя широко используемыми методами: Фримена-Кэрролла [20], Горовица-Метцгера [21], Коутса-Редферна [22].

Полученные при обработке одних и тех же результатов эксперимента кинетические параметры отличалась значительно (так, для эффективной энергии активации - примерно на $30 \%$ ) [10]. 
Ряд исследователей отмечает, что различия в предлагаемых для прогнозирования кинетики термического разложения доломита зависимостях в большей степени связаны с нестабильностью состава самого минерала (наличие примесей, различным стехиометрическое соотношением $\mathrm{Mg} / \mathrm{Ca}$ и другими факторами) [16].

Таким образом, несмотря на широкий фронт исследований, посвященных различным аспектам процесса термического разложения доломита, можно заключить, что они, мало продвигают инженерные методики расчета, позиционируя на протяжении десятилетий учет именно технологических факторов в качестве перспективной задачи (так на актуальность введения фактора размера частицы или массы образца указано в работах [5, 23]).

Цель данной работы состоит в определении значений кинетических параметров реакции термического разложения доломита в зависимости от размера (массы) исследуемого образца и температурного режима реализации процесса.

\section{МАТЕРИАЛЫ И МЕТОДЫ}

Доломитами принято называть минерал, который представляет собой двойную карбонатную соль кальция и магния $\left(\mathrm{CaMg}\left(\mathrm{CO}_{3}\right)_{2}\right)$ с примесями карбоната кальция $\left(\mathrm{CaCO}_{3}\right)$, окислов железа, алюминия, кремния, марганца и ряда других соединений [5-17]. Процентный состав белорусских доломитов приведен в таблице 1.

Таблица $1^{1}$.

Состав белорусских доломитов ${ }^{2}$ [24]

\begin{tabular}{|c|c|c|c|c|c|c|c|c|}
\hline $\begin{array}{c}\text { Соединение } \\
\text { (coalescence) }\end{array}$ & $\mathrm{SiO}_{2}$ & $\mathrm{Fe}_{2} \mathrm{O}_{3}$ & $\mathrm{Al}_{2} \mathrm{O}_{3}$ & $\mathrm{CaO}$ & $\mathrm{MgO}$ & $\mathrm{SO}_{3}$ & $\mathrm{~K}_{2} \mathrm{O}$ & $\mathrm{Na}_{2} \mathrm{O}$ \\
\hline \% масc.(\%mas) & 1,1 & 0,4 & 0,5 & 30,3 & 20,0 & 0,4 & 0,2 & 0,1 \\
\hline
\end{tabular}

В образце доломита в зависимости от температуры материала могут происходить последовательно и/или параллельно следующие химические реакции [15]: при температуре от $311.2^{\circ} \mathrm{C}$

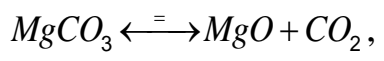

при температуре от $315.5^{\circ} \mathrm{C}$

$$
\mathrm{CaMg}\left(\mathrm{CO}_{3}\right)_{2} \stackrel{=}{\longleftrightarrow} \mathrm{CaCO}_{3}+\mathrm{MgO}+\mathrm{CO}_{2},
$$

при температуре от $331.9^{\circ} \mathrm{C}$

$$
\mathrm{CaMg}\left(\mathrm{CO}_{3}\right)_{2} \stackrel{=}{\longleftrightarrow} \mathrm{CaCO}_{3}+\mathrm{MgCO}_{3},
$$

при температуре от $538.2^{\circ} \mathrm{C}$

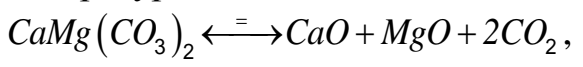

при температуре от $845.8^{\circ} \mathrm{C}$

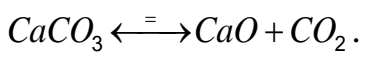

В настоящем исследовании было выполнено экспериментальное исследование процесса термического разложения образцов природного белорусского доломита. Опыты проводились в статических условиях при температурах от $500^{\circ} \mathrm{C}$ до $850^{\circ} \mathrm{C}$ (с шагом $\left.50^{\circ} \mathrm{C}\right)$. Вне зависимости от выбранного температурного режима и массы навески образец доломита помещался в специальной кювете в лабораторную печь SNOL7,2/1300 (ОАО «Умега»). Эта печь позволяет

1,2 Appendix 1 поддерживать постоянство температуры в интервале температур $500-1500^{\circ} \mathrm{C}$ с точностью $\pm 2{ }^{\circ} \mathrm{C}$. После достижения определенного периода времени кювета извлекалась из печи и взвешивалась на электронных весах (Stohl).

Согласно химическим уравнениям (1)-(5) в области рассматриваемых в настоящем исследовании температур магнезит $\left(\mathrm{MgCO}_{3}\right)$ полностью распадается до оксида магния и диоксида углерода. Последнее позволяет сам процесс образования магнезита не рассматривать в контексте работы. Также можно допустить, что на брутто-реакцию термопреобразования образца практически не оказывает влияние образование оксида кальция $(\mathrm{CaO})$, хотя теоретически оно возможно в последнем опыте (при $850^{\circ} \mathrm{C}$ ).

Метод электронной микроскопии был использован для дополнительной характеристики состояния как исходного материала, так после тепловой обработки. Микрофотографии были выполнены на сканирующем электронном микроскопе TESCAN MIRA 3 LMH (TESCAN, Чехия) позволяющем получить изображение поверхности исследуемого объекта с высоким разрешением, уточнив структурные особенности материала, наличие дефектов и включений на микро- и наноуровне 


\section{АНАЛИЗ РЕЗУЛЬТАТОВ}

На рисунке 1 представлены микрофотографии материала до и после тепловой обработки. Из рисунка 1 видно, что исходный доломит имеет кристаллическую структуру, которая заметно нарушается после его термической обработки. Обработанный материал содержит сравнительно большее количество пор и мелких структур. Последнее обстоятельство косвенно указывает на то, что диффузия углекислого газа $\left(\mathrm{CO}_{2}\right)$ происходит в затрудненных условиях, а эвакуация газа из образца сопровождается разрушением структуры

материала. Таким образом, построение адекватной физической модели продвижения и удаления $\mathrm{CO}_{2}$ из частиц материала, очевидно, является необходимым для совершенствования методик расчета систем очистки генераторных газов.

На рисунке 2 представлены примеры результатов экспериментальных термогравиметрических исследований по изучению динамики обжига частиц доломита разной массы при двух различных температурных режимах (в статических условиях при температурах $650^{\circ} \mathrm{C}$ и $\left.850^{\circ} \mathrm{C}\right)$.

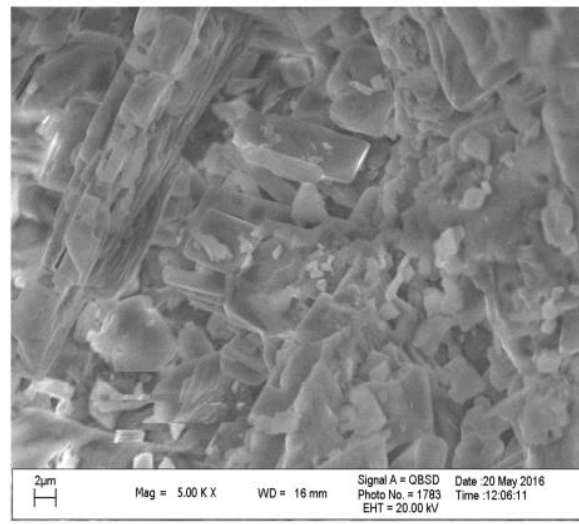

a)
Рис. 1. Микрофотографии неотожженного (а) и отожженного (б) доломита ${ }^{3}$

Частицы разных масс использовались и при проведении термогравиметрических опытов для других исследованных температурных режимов. В качественном отношении результаты этих экспериментов оказались хорошо согласованными. В частности, было определено, что при температуре до $500-550^{\circ} \mathrm{C}$ химические процессы, определяющие брутто-реакцию

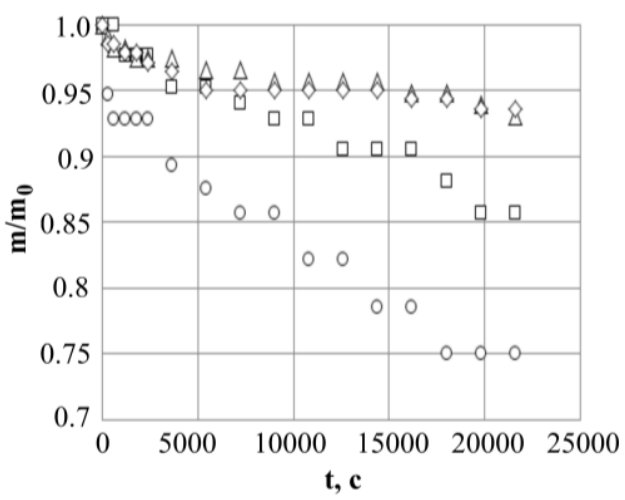

a)

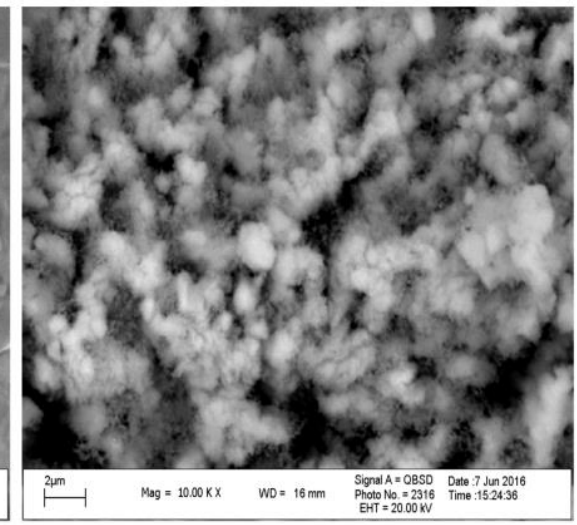

б) разложения доломитов, происходят крайне медленно. В потерю массы частицами при этой температуре вносит вклад испарение гигроскопической воды в исходных образцах. При этом гигроскопичность мелкой крошки $(\mathrm{m}<0,58 \quad$ г) необожженного доломита составляет от 5 до $7 \%$.

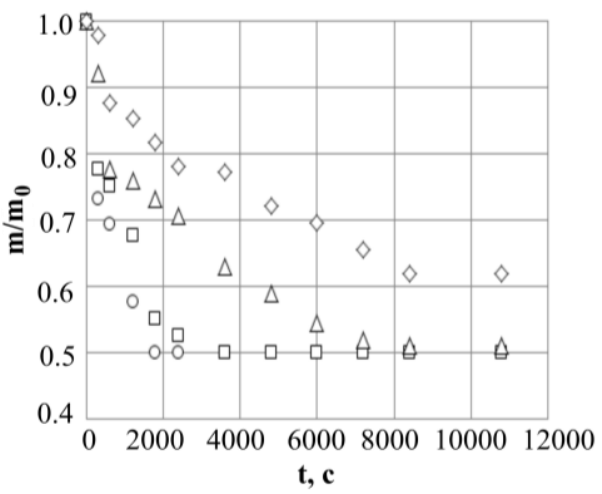

б)

о- начальная масса образиа $m_{0}=0.58$ 2, 口- начальная масса образиа $m_{0}=0.88$ г, $\Delta$ - начальная масса образияа $m_{0}=2.3$ г, $\diamond$ - начальная масса образиа $m_{0}=2.72$.

Рис. 2. Динамика изменения относительной массы частиц доломита при обжиге при температурах $650^{\circ} \mathrm{C}\left(\right.$ a) и $850^{\circ} \mathrm{C}(\text { б })^{4}$ 
Более крупная крошка $(\mathrm{m}>0,58$ г) имеет гигроскопичность от 0 до $3 \%$. При этом время выхода влаги из доломита составляет от 5 до 10 мин. В случае использования более высоких температур (выше $600^{\circ} \mathrm{C}$ ) разложение доломита становится заметным, ускоряется с ростом температуры и уменьшением массы частиц, что подтверждается данными рис. 2. Зависимость степени разложения от массы образца указывает на существенное влияние процесса эвакуации молекул углекислого газа $\left(\mathrm{CO}_{2}\right)$ из объема образца.

Полученные экспериментальные данные были проанализированы на основе кинетических уравнений, применяемых при исследовании термического разложения доломита, а также других твердофазных процессов. Значение степени разложения определялось по выражению [12-16]:
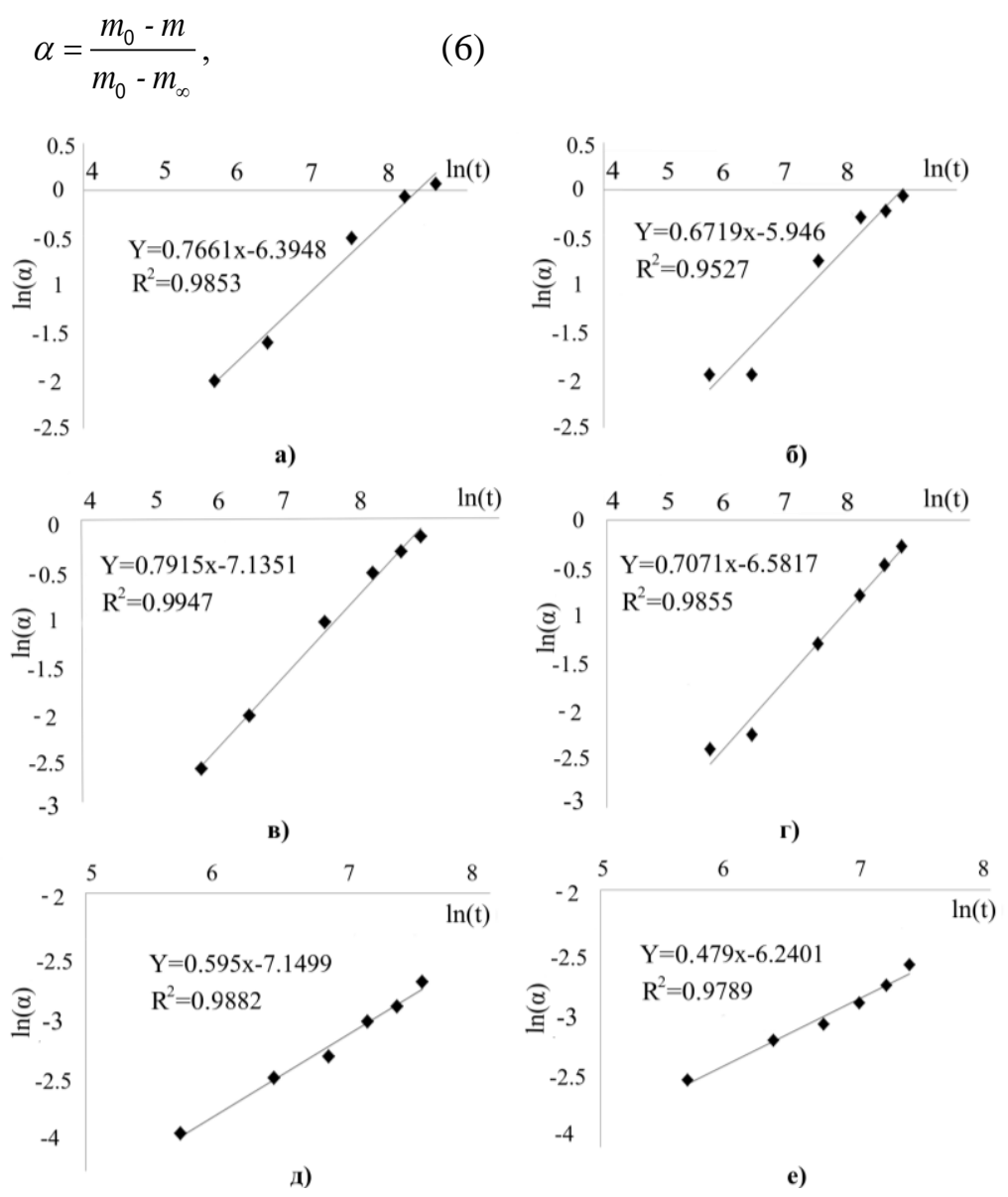

маркеры - экспериментальные значения, линии - расчетные значения:

$a$ - начальная масса образиа $m_{0}=0,58$ г; б - начальная масса образиа $m_{0}=0,88$ г; в - начальная масса образиа $m_{0}=2,3$ г; г - начальная масса образиа $m_{0}=2,6$ г; д - начальная масса образиа $m_{0}=7,6$ г; е-начальная масса образца $m_{0}=16,3$ г.

Рис. 3. Зависимость значения логарифма степени превращения $\alpha$ от логарифма времени тепловой обработки при $800{ }^{\circ} \mathrm{C} .{ }^{5}$ где $\mathrm{m}_{0}$ - масса исходного образца, г., $\mathrm{m}$ масса образца в текущий момент времени, г., $\mathrm{m}_{\infty}$ - минимальное значение массы образца, остигаемое в эксперименте, г.

На предыдущих этапах исследования нами было установлено, что наиболее точное кание кинетики термического разложения доломитов Беларуси дает - эмпирический параметр, $\mathrm{k}$ - константа брутто-реакции, $\mathrm{t}-$ время

примет вид:

$$
\ln (\alpha)=(\ln (k)+\ln (t)) / n \text {. }
$$


Данные, представленные на рисунке 3, показывают зависимость $\ln (\alpha)$ от $\ln (\mathrm{t})$, построенную на основании эмпирических значений степени разложения, установленных в опытах по термическому разложению образца природного доломита Беларуси при температуре $800^{\circ} \mathrm{C}$.

Для получения адекватного уравнения, который приводит к линейности функции $\ln (\mathrm{k})$ от $\ln (\mathrm{t})$ использован метод наименьших квадратов. Такая линейная зависимость возможна только в случае коэффициента детерминации $\mathrm{R}^{2}$ аппроксимации значений этой функции от $\ln (\mathrm{t})$ близкого 1. Данное обстоятельство было использовано при выборе (методом перебора) для каждого эксперимента конкретных параметров линейной зависимости $\mathrm{Y}=\mathrm{f}(\mathrm{x})$, где $\mathrm{Y}=\ln (\mathrm{k}), \mathrm{x}=$ $\ln (\mathrm{t})$. Полученные зависимости также представлены на рис. 3.

В таблице 2 представлены значения констант скорости термического разложения частиц доломита различной массы, полученные при анализе результатов всех экспериментов (для различных температур и масс навесок) и использовании уравнения (8). Из приведенных данных можно заключить, что для любой используемой температуры константа скорости существенно зависит от массы образца и для исследованного диапазона размеров отличается на 1-2 порядка.

Таблица $2^{6}$.

Константы скорости термического разложения природных доломитов ${ }^{7}$

\begin{tabular}{|c|c|c|c|c|c|}
\hline $\mathrm{T}, \mathrm{K}$ & 923 & 973 & 1023 & 1073 & 1123 \\
\hline \multicolumn{6}{|c|}{$\mathrm{m}=0.58 \Gamma$} \\
\hline $\mathrm{k}, \mathrm{c}^{-1}$ & $1.46667 \cdot 10^{-5}$ & $2.6716 \cdot 10^{-5}$ & $1.0312 \cdot 10^{-4}$ & $2.055 \cdot 10^{-4}$ & $7.6003 \cdot 10^{-4}$ \\
\hline \multicolumn{6}{|c|}{$\mathrm{m}=0.88 \Gamma$} \\
\hline $\mathrm{k}, \mathrm{c}^{-1}$ & $7.2 \cdot 10^{-6}$ & $3.6466 \cdot 10^{-6}$ & $3.7889 \cdot 10^{-5}$ & $1.4346 \cdot 10^{-4}$ & $3.1364 \cdot 10^{-4}$ \\
\hline \multicolumn{6}{|c|}{$\mathrm{m}=2.3 \Gamma$} \\
\hline $\mathrm{k}, \mathrm{c}^{-1}$ & $4.2 \cdot 10^{-7}$ & $5.949 \cdot 10^{-6}$ & $2.2043 \cdot 10^{-5}$ & $1.2161 \cdot 10^{-4}$ & $2.6672 \cdot 10^{-4}$ \\
\hline \multicolumn{7}{|c|}{$\mathrm{m}=2.7 \Gamma$} \\
\hline $\mathrm{k}, \mathrm{c}^{-1}$ & $2.53333 \cdot 10^{-7}$ & $7.0918 \cdot 10^{-6}$ & $2.3578 \cdot 10^{-5}$ & $9.0694 \cdot 10^{-5}$ & $2.7288 \cdot 10^{-4}$ \\
\hline \multicolumn{7}{|c|}{$\mathrm{m}=7.6 \Gamma$} \\
\hline $\mathrm{k}, \mathrm{c}^{-1}$ & $2.0013 \cdot 10^{-6}$ & $2.7902 \cdot 10^{-6}$ & $6.05 \cdot 10^{-6}$ & $3.976 \cdot 10^{-5}$ & $9.366 \cdot 10^{-5}$ \\
\hline \multicolumn{7}{|c|}{$\mathrm{m}=16.3 \Gamma$} \\
\hline $\mathrm{k}, \mathrm{c}^{-1}$ & $6.607 \cdot 10^{-7}$ & $2.396 \cdot 10-6$ & $2.2 \cdot 10^{-6}$ & $1.774 \cdot 10^{-5}$ & $7.488 \cdot 10^{-5}$ \\
\hline
\end{tabular}

На рисунке 4 представлены графики зависимости $\ln (\mathrm{k})$ от $\ln (1 / \mathrm{m})$ (логарифма обратной величины начальной массы частицы) для некоторых температурных режимов обработки образцов.

Из рисунка 4 видно, что в пределах рассматриваемых масс частиц зависимость $\ln (\mathrm{k})$ от $\ln (1 / \mathrm{m})$ имеет линейный вид, а угол наклона графиков практически не зависит от температуры. В общем виде зависимость описывается выражением

$$
\ln (k)=C \cdot \ln (1 / m)+B,
$$

где $\mathrm{C}-$ безразмерный эмпирический параметр, связанный с углом наклона и имеющий постоянное значение $(\mathrm{C}=0.88), \mathrm{B}-$ эмпирический параметр, не зависящий от массы образца.
Константа скорости может быть выражена из выражения (9) в форме аррениусовского уравнения

$$
k=f(m) \cdot A \exp (-E / R \cdot T),
$$

где $\mathrm{f}(\mathrm{m})$ - эмпирическая функция массы образца (для рассматриваемого процесса с учетом измерения массы в килограммах $\left.\mathrm{f}(\mathrm{m})=(1000 / \mathrm{m})^{\mathrm{C}}\right), \quad$ А $\quad$ и $\quad$ Е предэкпоненциальный параметр и энергия активации процесса. На предшествующих этапах исследования нами были получены кинетические параметры этого соотношения, что позволяет записать его в виде:

$$
k=(1000 / m)^{C} \cdot A \exp (-E / R \cdot T),
$$

$\mathrm{A}=1050000$ мин $^{-1}, \mathrm{E}=203000$ Дж/моль. 
В настоящем исследовании сделано допущение, что частицы доломита имеют форму шара, тогда выражение (11) можно преобразовать в зависимость константы скорости от радиуса частицы:

$$
k=118490 \cdot r^{-2.64} \cdot \exp (-203000 / R \cdot T),
$$

где $\mathrm{r}$ - эквивалентный радиус частицы, м.

На рисунке 5 представлены графики зависимости константы скорости от массы (в килограммах) для различных температур.

Из рисунка 5 видно, что расчетные значения константы скорости достаточно хорошо согласуются с результатами экспериментов для всех рассматриваемых масс частиц и температурных режимов обработки материала, что указывает на целесообразность использования выражений (11) и (12) при расчете константы скорости термического разложения доломита.

\section{РАЗРАБОТКА ПИЛОТНОЙ СИСТЕМЫ ОЧИСТКИ ГЕНЕРАТОРНЫХ ГАЗОВ}

Полученные в настоящей работе эмпирические зависимости (11)-(12) представляют собой нетривиальный результат, продвигающий инженерные методы расчета систем очистки генераторных газов. С одной стороны эти зависимости получены при грубом для термогравиметрического анализа допущении, что размер частицы влияет на результат анализа (обычно используется минимально возможная масса навески, для которой инструментально можно фиксировать изменение массы). С другой стороны именно такая постановка эксперимента позволяет ввести в инженерные методы расчета массу частиц в качестве технологического фактора, влияющего на целевой процесс.

Логичным следующим шагом жизненного цикла процесса является его аппаратурное оформление и поиск средств для его адекватного описания. На данном этапе было принято решение о разработке пилотной установки очистки генераторных газов, чтобы в дальнейшем по результатам исследования параметров ее функционирования принять решение о выборе средств ее математического описания. На рисунке 6 показаны основные элементы разработанной установки.

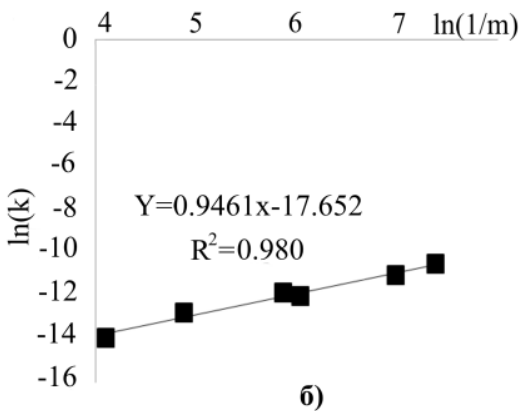

a)
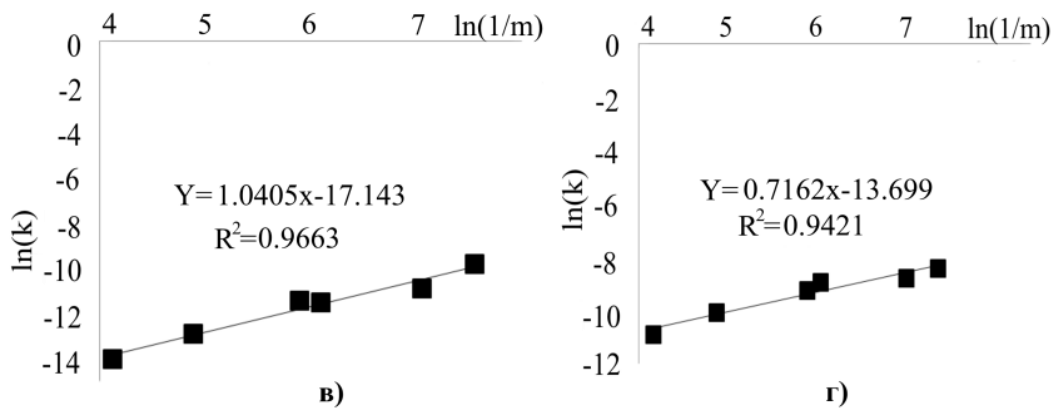

г)

маркеры - экспериментальные значения, линии - расчетные значения: $a-650^{\circ} \mathrm{C} ; 6-700^{\circ} \mathrm{C} ; 8-750^{\circ} \mathrm{C} ; 2-800^{\circ} \mathrm{C}$.

Рис. 4. Графики зависимости $\ln (k)$ от $\ln (1 / \mathrm{m})$ для различных температур. ${ }^{8}$ 

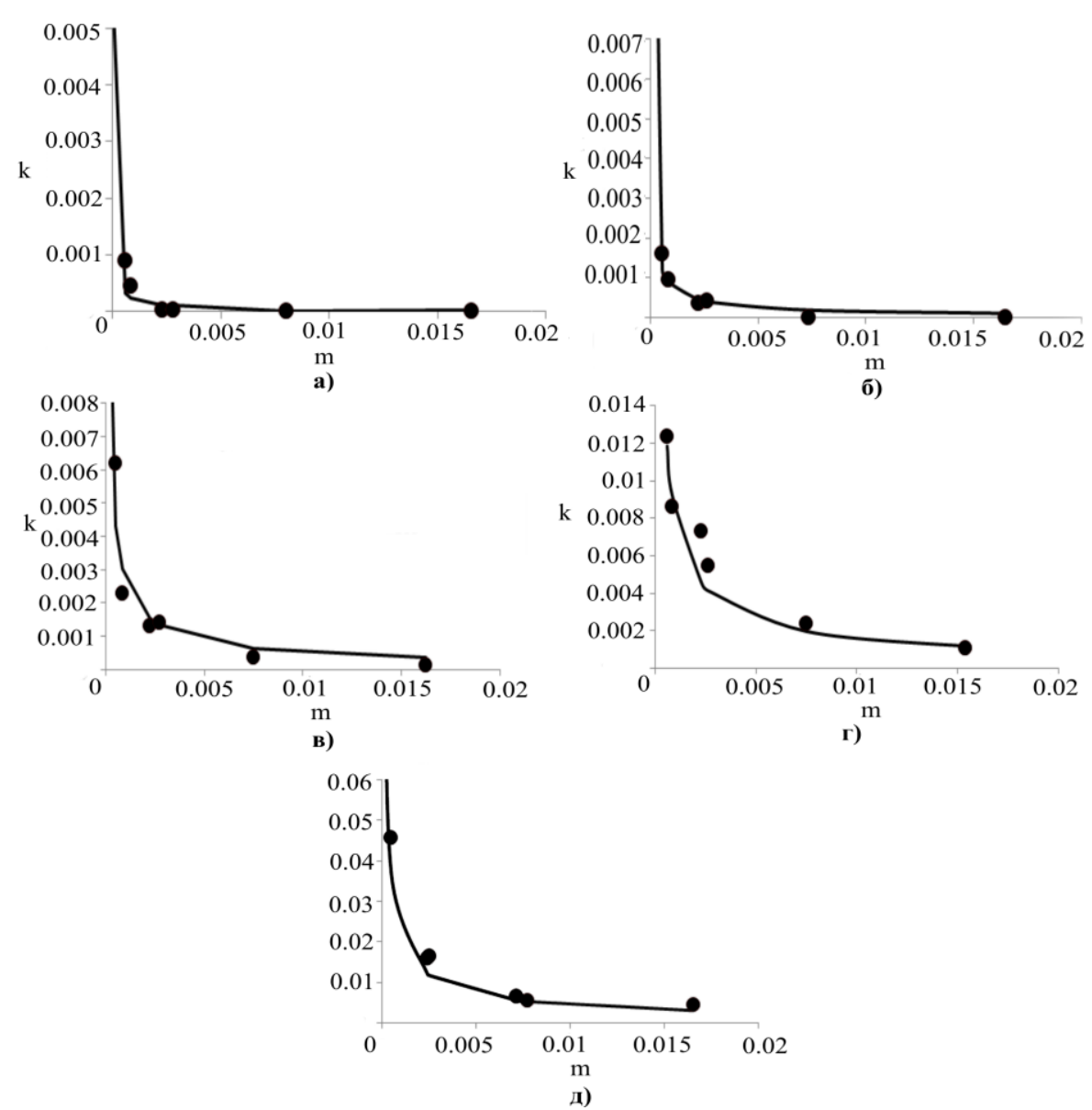

маркеры - экспериментальные значения, линии - расчетные значения: $a-650^{\circ} \mathrm{C} ; \sigma-700^{\circ} \mathrm{C} ; 8-750^{\circ} \mathrm{C} ; 2-800^{\circ} \mathrm{C}, \partial-850^{\circ} \mathrm{C}$.

Рис. 5. Графики зависимости константы скорости термического разложения доломита от массы Здля различных температур. ${ }^{9}$

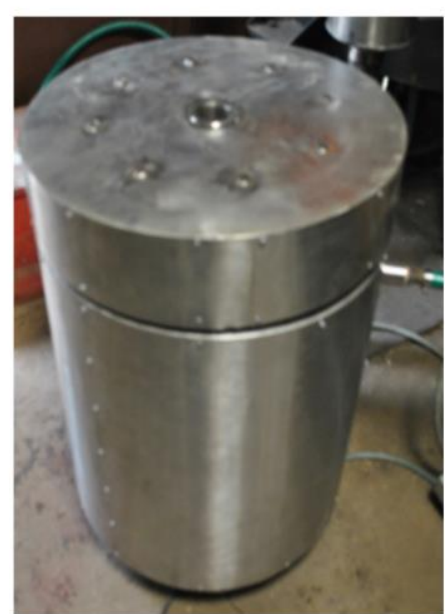

a)

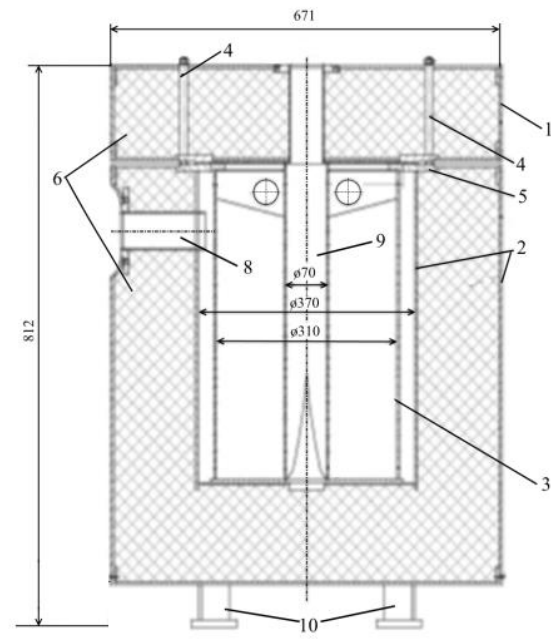

б)

1 - крышка; 2 - корпус; 3 - кассета (рабочая камера); 4 -система крепления крышки к корпусу; 5 - прокладка; 8-входной патрубок; 9 - выходной коллектор; 10 -регулируемые опорыл.

Рис. 6. Общий вид (а) и чертеж (б) экспериментального образца реактора очистки с радиальноаксиальным движением газов. ${ }^{10}$

\footnotetext{
${ }^{9,10}$ Appendix 1
} 
Реактор представляет собой три цилиндрические емкости с различными диаметрами, расположенные соосно. Внутренняя и средняя цилиндрические поверхности перфорированы с количеством отверстий 246 отверстий на внутренней поверхности и 2050 на средней (диаметр отверстий перфорации - 4 мм). В пространство между перфорированным цилиндрами засыпается сорбент (доломит). Реактор очистки работает следующим образом. Газовый агент поступает через входной патрубок во входной коллектор с шириной зазора 30 мм, проходит через перфорированную стенку среднего цилиндра, фильтруется в аксиально-радиальном направлении через слой катализатора, вступая в реакцию. Затем прореагировавший газ через пористую стенку внутреннего цилиндра поступает в центральную полость (выводной коллектор) диаметром 70 мм. Сверху каналы между цилиндрическими поверхностями герметизированы, а из выходного коллектора обеспечивается вывод газового агента выходит из реактора.

Каталитический реактор очистки устанавливается после устройства пиролиза для улучшения технологических свойств получаемого газа. Реактор содержит засыпку катализатора, в объеме которого протекают химические реакции, что позволяет уменьшить содержание смол и сажи, стабилизирует состав пиролизного газа. В реакторе радиального типа газы входят в слой и выходят из слоя катализатора через боковые стенки коллекторов. Движение газа в слое катализатора по направлению перпендикулярно течению в коллекторах. Скорость внутри засыпки может быть значительно меньшей, чем в коллекторах.

Для применения в качестве засыпки в радиальном реакторе, в частности, обработки синтез-газа пиролиза древесины, предпочтительны монодисперсные засыпки изомерных частиц в диапазоне диаметров 110 мм. Конструкция реактора предусматривает возможность работы с засыпками монодисперсных частиц разных размеров.

В ходе выполнения работ была собрана линия получения и очистки топливного газа, получаемого путем термохимической конверсии древесины, принципиальная схема которой представлена на рисунке 7.

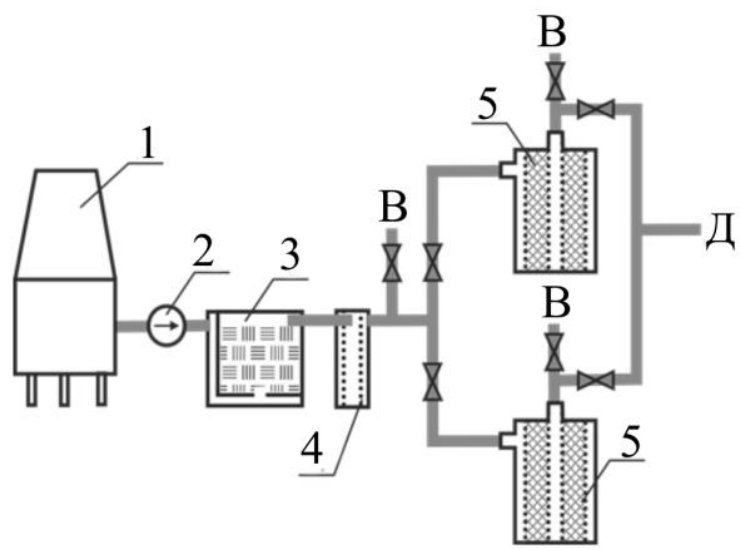

1 - газогенератор; 2 - скруббер Вентури с насосом, водоотделительным ящиком и сточной емкостью, 3 - фильтр тонкой очистки ø700 мм; 4 - контрольный фильтр ø300 мм; 5 - реактор очистки топливного газа с радиально-аксиальным движением потока с применением доломита; $B$ - коллектор, ведущий к факельную установку с регулирующим вентилем; Д - коллектор, ведущий к газопоршневому двигателю с электрогенератором.

Рис. 7. Принципиальная схема подключения двух реакторов очистки топливного газа с радиальноаксиальным движением потока с использованием доломита. ${ }^{11}$

Поскольку время работы доломитового реактора на стадии сорбции ограничено, необходимо оптимизировать работу установки таким образом, чтобы она работала постоянно. С этой целью была разработана и реализована система с двумя радиальноаксиальными реакторами, работающими в цикле (рис. 7). В то время, когда в одном реакторе осуществляется обжиг доломита, во 
втором идет стадия сорбции. По окончании этих стадий реакторы переключаются.

Генераторные газы, поступившие после первичной очистки, поступают в общий газоход, откуда идут в реактор, работающий на стадии сорбции, после которого поступает в газопоршневой двигатель. Газы, отходящие из реактора, работающего на стадии обжига, поступают непосредственно на выхлоп.

Необходимо отметить, что полученные в настоящем исследовании результаты (в первую очередь, зависимость кинетических параметров брутто-реакции от размера исходной частицы) обладают практической значимостью, так как могут быть включены в различные методики расчета сорбционнокаталитических систем очистки газа на основе доломита, повышая достоверность описания процесса и качество прогнозирования его параметров.

При этом нельзя игнорировать то обстоятельство, что переход к аппаратурному оформлению технологического процесса очистки генераторного газа требует не только знаний о реакции материала на те или иные воздействия, но и адекватной модели функционирования аппарата. В рамках продолжения работы по совершенствованию методов прогнозирования и расчета работы сорбционных систем очистки генераторного газа нами будет предложена математическая модель фильтрации генераторного газа через слой частиц доломита при протекании сорбционно-каталитических процессов. В качестве численной основы решения этой задачи будут использованы элементы математического аппарата теории цепей Маркова и явные разностные схемы. Использование этих математических инструментов позволит выполнить описание процесса в аппарате, как в объекте с распределенными параметрами. Для верификации модели будет использована экспериментальная система, показанная на рис. 7 , при этом будут исследованы режимы с различными фракциями частиц доломита. Рассмотрение ансамблей частиц (навесок материала в аппарате) как объектов с распределенными характеристиками и применение зависимостей (11)-(12) при расчете константы скорости термического разложения доломита для учета влияния размера частиц в этих навесках, на наш взгляд, обеспечит повышение адекватности описания технологического процесса и повысит качество его прогнозирования.

\section{ВЫВОДЫ}

1. Результаты анализа экспериментального исследования термического разложения природного доломита, выполненного в изотермических условиях на лабораторном оборудовании при температурах $650^{\circ} \mathrm{C}$, $700^{\circ} \mathrm{C}, 750^{\circ} \mathrm{C}, 800^{\circ} \mathrm{C}$ и $850^{\circ} \mathrm{C}$, показали, что скорость реакции термического разложения доломита зависит не только от температурного режима в реакционной зоне, но и в значительной мере определяется массой исследуемых образцов.

2. Установлено, что константа скорости термического разложения доломита в исследуемом диапазоне масс образцов может быть определена по эмпирическому выражению, идентифицированному в ходе настоящего исследования:

$$
k=(1000 / m)^{C} \cdot A \exp (-E / R \cdot T),
$$

где $\mathrm{C}$ - эмпирический параметр $(\mathrm{C}=0.88), \mathrm{A}-$ предэкпоненциальный параметр реакции термического разложения доломита $\left(\mathrm{A}=1050000\right.$ мин $\left.^{-1}\right), \mathrm{E}-$ энергия активации ( $\mathrm{E}=203000$ Дж/моль).

3. Исследование показывает высокий уровень согласованности значений констант скорости, полученных эмпирическим путем, и рассчитанных по выражению (11) с учетом массы образцов. Это указывает на то, что разработанная модель является физически обоснованной, а предложенная в работе зависимость может быть инкорпорирована в существующие инженерные методики расчетов систем очисти генераторных газов, использующих доломит в качестве сорбента.

4. Результаты исследования представляют самостоятельный интерес $\mathrm{c}$ точки зрения тривиального их развития. В частности, одним из очевидных продолжений данной работы может стать моделирование конкретного технологического процесса, использующего доломит, при помощи предложенной модели. Для использования модели термического разложения одиночной частицы предложена пилотная установка очистки топливного газа с радиальноаксиальным движением потока с использованием доломита. Представляет 
интерес также применение разработанного подхода для построения моделей обратного процесса, например, поглощения углекислого газа оксидами кальция и магния.

5. В исследовании показано, что проблемы накопления и эвакуации газообразных продуктов реакции из образцов доломита при его термическом разложении представляют собой самостоятельную проблему, от успешности решения которой во многом зависит возможность целенаправленного управления процессом очистки генераторного газа. Так как процесс продвижения и выхода $\mathrm{CO}_{2}$ из образца влияет и на кинетику химических превращений, и на структуру получаемого материала, то требуется разработка физико-математических моделей этого явления, как процесса с распределенными и нестационарными (до завершения всех химических превращений) пространственными параметрами. В то же время, несмотря на выбор численных алгоритмов решения этой задачи, в качестве внутреннего параметра численной модели будет востребована зависимость для описания разложения доломита в точечной области. Таким образом, предложенное в настоящей работе эмпирическое соотношение является эмпирической поддержкой решения задач численного моделирования.

6. В работе представлена схема системы по очистке генераторного газа, получаемого путем термохимической конверсии органического сырья. Система включает в себя два каталитических реактора риформинга с радиально-аксиальным движением потока газов через слой доломита.

\section{APPENDIX 1 (ПРИЛОЖЕНИЕ 1)}

1,2Table 1. The composition of the Belarusian dolomites.

${ }^{3}$ Fig. 1. Micrographs of unburned (a) and annealed (b) dolomite.

${ }^{4}$ Fig. 2. Dynamics of changes in the relative mass of dolomite particles during treatment at temperatures of $650^{\circ} \mathrm{C}$ (a) and $850^{\circ} \mathrm{C}$ (b).

${ }^{5}$ Fig. 3. The dependence of the logarithm of the degree of transformation $\alpha$ on the logarithm of the heat treatment time at $800{ }^{\circ} \mathrm{C}$.

${ }^{6,7}$ Table 2. Constants of the rate of thermal decomposition of natural dolomites.

${ }^{8}$ Fig. 4. Graphs of the dependence of $\ln (\mathrm{k})$ on $\ln (1 / \mathrm{m})$ for different temperatures.

${ }^{9} \mathbf{F i g}$. 5. Graphs of the dependence of the rate constant of thermal decomposition of dolomite on the mass for different temperatures.
${ }^{10}$ Fig. 6. General view (a) and drawing (b) of an experimental sample of a purification reactor with radial-axial movement of gases.

${ }^{11}$ Fig. 7. Schematic diagram of connection of two fuel gas purification reactors with radial-axial flow motion using dolomite.

\section{Литература (References)}

[1] Fortov V.E., Popel' O.S. The Current Status of the Development of Renewable Energy Sources Worldwide and in Russia. Thermal Engineering, 2014, vol. 61, no.6, pp. 389-398.

[2] De S., Agarwal A.K., Moholkar V.S., Bhaskar T. Coal and Biomass Gasification. Recent Advances and Future Challenges. Springer Nature, Singapore Pte Ltd., 2018, 521 p.

[3] Afanas'eva O.V., Mingaleeva G.R. Energy Efficiency of Small Coal-Fired Power Plants as a Criterion of Their Wide Applicability. Solid Fuel Chemistry, 2009, vol. 43, no. 1, pp. 55-59.

[4] Hu G., Xu S., Li S., Xiao C., Liu S. Steam Gasification of Apricot Stones with Olivine and Dolomite as Downstream Catalysts. Fuel Processing Technology, 2006, Vol. 87, No. 5, p. 375-382.

[5] Dobrego K.V. Makrokineticheskie Modeli Termicheskogo Razlozheniya Dolomita dlya Rascheta Sorbtsionnykh Sistem Gazogeneratorov [Dolomite Thermal-Decomposition Macrokinetic Models for Evaluation of the Gasgenerators Sorbent Systems]. Energetika. Proceedings of CIS Higher Education Institutions and Power Engineering Associations, 2015, no. 5, pp. 51-59. (In Russian).

[6] Rat'ko A.I., Ivanets A.I., Kulak A.I., Morozov E.A., Sakhar I.O. Thermal Decomposition of Natural Dolomite. Inorganic Materials, 2011, vol. 47, no.12, pp. 1372-1377.

[7] Rodriguez-Navarro C., Ruiz-Agudo E., Luque A., Rodriguez-Navarro A.B., Ortega-Huertas M. Thermal Decomposition of Calcite: Mechanisms of Formation and Textural Evolution of $\mathrm{CaO}$ Nanocrystals. American Mineralogist, 2009, vol. 94, pp. 578-593.

[8] Rodriguez-Navarro C., Kudlacz K., Ruiz-Agudo E. The Mechanism of Thermal Decomposition of Dolomite: New Insights from 2D-XRD and TEM Analyses. American Mineralogist, 2012, vol. 97(1), pp. 38-51.

[9] Maitra S., Chowdhury A., Das H., Pramanik Ms. Effect of Compaction on the Kinetics of Thermal Decomposition of Dolomite under NonIsothermal Condition. Journal of Materials Science, 2005, vol. 40, pp. 4749-4751.

[10] Gunasekaran S., Anbalagan G. Thermal Decomposition of Natural Dolomite. Bulletin of Materials Science, 2007, vol. 30, pp. 339-344.

[11] Beruto D.T., Vecchiattini R., Giordani M. Solid Products and Rate-Limiting Step in the Thermal 
Half Decomposition of Natural Dolomite in a CO2 (G) Atmosphere. Thermochimica Acta, 2003, vol. 405, pp. 183-194.

[12] Rat'ko A.I., Ivanets A.I., Kulak A.I., Morozov E.A., Sakhar I.O. Thermal Decomposition of Natural Dolomite. Inorganic Materials, 2011, vol. 47, no.12, pp. 1372-1377.

[13] Olszak-Humienik M., Możejko J. Kinetics of Thermal Decomposition of Dolomite. Journal of Thermal Analysis and Calorimetry, 1999, vol. 56, pp. 829-833.

[14] Samtani M., Dollimore D., Alexander K. Comparison of Dolomite Decomposition Kinetics with Related Carbonates and the Effect of Procedural Variables on its Kinetic Parameters. Thermochim. Acta, 2002, no. 392-393, pp. 135-145.

[15] Olszak-Humienik M., Jablonski M. Thermal Behavior of Natural Dolomite. Journal of Thermal Analysis and Calorimetry, 2015, vol. 119, pp. 22392248.

[16] Hartman M., Trnka O., Vesely V., Svoboda K. Predicting the Rate of Thermal Decomposition of Dolomite. Chemical Engineering Science, 1996, vol. 51, no. 23, pp. 5229-5232.

[17] Barcina LM, Espina A, Sua`rez M, Garcia JR, Rodriguez J. Characterization of Monumental Carbonate Stones by Thermal Analysis (TG, DTG and DSC). Thermochim. Acta. 1997, vol. 290, pp. 181-189.

[18] L'vov BV. Mechanism and Kinetics of Thermal Decomposition of Carbonates. Thermochim. AcСведения об авторах.
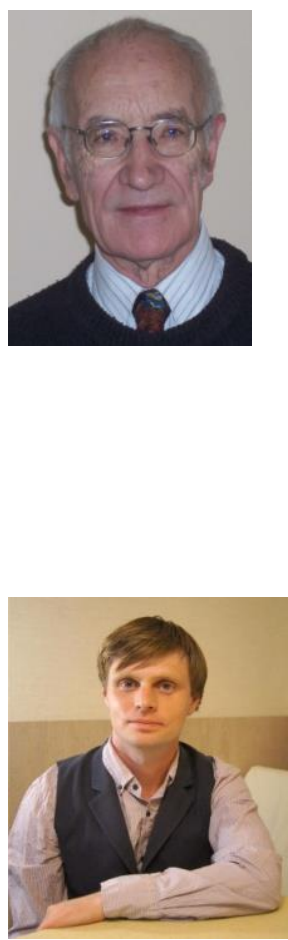

Малько Михаил Владимирович, кандидат физико-математических наук, ведущий научный сотрудник Института энергетики НАН Беларуси, Республика Беларусь. Область научных интересов: возобновляемая энергетика, получение биотоплив.

E-mail: mikhailvm@bas-net.by

\section{Митрофанов Андрей Васильевич, доктор технических наук, Ива- новский государствен- ный энергетический университет, Россий- ская Федерация. Область научных интересов: про- цессы в кипящем слое. E-mail: and2mit@mail.ru}

ta, 2002, vol. 386, pp.1-16.

[19] Kozlov A.N., Svischev D.A., Khudyakova G.I., Ryzhkov A.F. Kineticheskii Analiz Termohimicheskoi Konversii Tverdykh Topliv. Himiya Tverdogo Topliva [Kinetic Analysis of Thermochemical Conversion of Solid Fuels]. Chem. Sol. Fuel, 2017, no.4, pp.12-21. (in Russian)

[20]Freeman E.S, Carroll B. The Application of Thermoanalytical Techniques to Reaction Kinetics: the Thermogravimetric Evaluation of the Kinetics of the Decomposition of Calcium Oxalate Monohydrate. J. Phys. Chem. 1958, vol. 62, pp. 394-397.

[21] Horowitz H.W., Metzger G. A New Analysis of Thermogravimetric Traces. Analytical Chemistry, 1963, vol. 35, no.10, 1464-1468.

[22] Coats A.W., Redfern J.P. Kinetic Parameters from Thermogravimetric Data. Nature. 1964, vol. 201, no.4914, pp. 68-69.

[23] Sharp J.H., Wilburn F.W., McIntosh R.M. The Effect of Procedural Variables on TG, DTG and DTA Curves of Magnesite and Dolomite. Journal of Thermal Analysis. 1991, vol. 37, pp. 20212029.

[24] Rat'ko A.I., Ivanets A.I., Sakhar I.O., Davydov D.Y., Toropova V.V., Radkevich A.V. A Sorbent Based on Natural Dolomite for Recovery of Cobalt Radionuclides. Radiochemistry. 2011. vol. 53, no. 6, pp. 633-637.

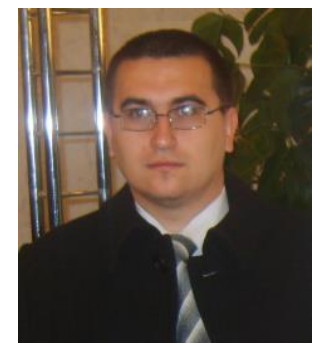

Василевич Сергей Владимирович, кандидат технических наук, доцент Белорусской государственной академии авиации, Республика Беларусь. Область научных интересов: возобновляемая энергетика, получение биотоплив. E-mail: svasilevich@yandex.ru

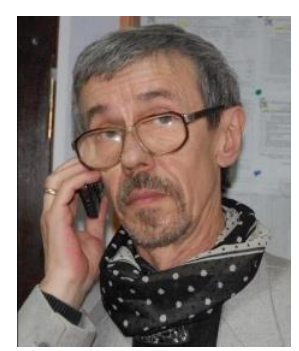

Мизонов Вадим Евгеньевич, доктор технических наук, Ивановский государственный энергетический университет, Российская Федерация. Область научных интересов: применение теории цепей Маркова в химической инженерии. E-mail: mizonov46@mail.ru 